\title{
Methodological Approach to Substantiating the Volume of Academic Hours for the Educational Process in Higher Military Educational Institutions Using the Weibull-Gnedenko Nonlinear Mathematical Model
}

\author{
Liliia Semenenko ${ }^{1, *}$, Serhii Kirsanov ${ }^{2}$, Petro Onofriichuk ${ }^{3}$, Mykola Vasianovych ${ }^{4}$ \& Ihor Levchenko ${ }^{5}$ \\ ${ }^{1}$ Department of Foreign Languages, National Defense University of Ukraine named after Ivan Cherniakhovsky, Kyiv, \\ Ukraine \\ ${ }^{2}$ Department of Automated Control Systems, Central Research Institute of the Armed Forces of Ukraine, Kyiv, \\ Ukraine \\ ${ }^{3}$ Department for Forecasting the Development of the Armed Forces of Ukraine, Central Research Institute of the \\ Armed Forces of Ukraine, Kyiv, Ukraine \\ ${ }^{4}$ Central Research Institute of the Armed Forces of Ukraine, Kyiv, Ukraine \\ ${ }^{5}$ Department of Supply of Fuel and Lubricants, Military Academy, Odesa, Ukraine \\ *Correspondence: Department of Foreign Languages, National Defense University of Ukraine named after Ivan \\ Cherniakhovsky, 03049, 28 Vozdukhoflotsky Ave., Kyiv, Ukraine. Tel: 380-44-248-1078. E-mail: \\ 1.semenenko7784@uohk.com.cn
}

Received: November 1, 2021

Accepted: Janaury 28, 2022 Online Published: February 10, 2022

doi:10.5430/jct.v11n2p66

URL: https://doi.org/10.5430/jct.v11n2p66

\begin{abstract}
High requirements for professional training of Defence Specialists were and remain the main guarantee of successful functioning of any military structure. Continuous improvement of the educational process in higher military educational institutions is the basis for its transformation to the conditions of the current situation in the world. In the paper, the authors offer an option to determine the number of classroom hours. This project describes approaches to creating a new, modern system of classroom hours, which ensures the continuity of improving the level of professional competence of higher military educational institutions using the nonlinear mathematical model of Weibull-Gnedenko. Organisational and methodological problems were analysed. Because of the analysis of methodological literature, the points of view of teachers and methodologists are compared on the modern methodological work, and a mathematical model was used that established the relationship between the training level of students and the number of academic hours. The proposed model divides the educational process into initial and main periods. The learning process strengthens in the main period. There is a slowdown at the beginning and end.
\end{abstract}

Keywords: training level, study hours, inflexion point, training period, mathematical model

\section{Introduction}

Any educational process is based on curricula and programmes. To do this, training subjects are chosen from the established plan, corresponding to a certain speciality and containing a certain amount of information in order to improve the level of knowledge, skills and abilities (Avramenko \& Kucher, 2020). The goal is also to restore previously received information in the memory of students (cadets, officers). At the same time, teachers focus their attention on evaluating the results of classes, taking into account the specifics of each speciality.

All this suggests that it is advisable to train students (cadets, officers) in special areas of training, using a comprehensive programme. It should take into account the specifics and features of these specialists, their initial training, duration of training and availability of resources, as well as the procedure for assessing the quality of knowledge. Therefore, the question arises of how to determine the required number of training hours and achieve the greatest efficiency. This highlights the relevance of this study. 
Many scientists and methodologists deal with this issue. Each HEI (higher education institution) or military higher education institution (MHEI) has its programmes and curricula, methods and approaches. Much attention is paid to the system of assessing students' knowledge. S.N. Belova (2008) defines goals and principles of maintaining a grade-rating system for assessing the quality of student training, determines the conditions for its introduction, and identifies the components of this system. N.V. Bogdan (2010) proposed the author's system of grade-rating assessment. B.E. Starichenko (2013) provided an algorithm for determining the volume of a student's academic load and a scheme for evaluating its results. Examples are given of planning the basic minimum of an academic discipline with calculations of labour intensity. The authors offer a comprehensive approach to the implementation of the tasks of the Bologna Process at the level of universities and subject areas (Setting up educational structures in Europe..., 2021). A methodology is proposed for the development, implementation and evaluation of educational programmes. Learning outcomes are determined by the level of knowledge that students receive. E.S. Pavlova considers a rating system for monitoring the training of specialists (Pavlova, 2014). However, in these works, the authors do not establish a functional relationship between the training level of students (cadets, officers) and the offered number of training hours. To a certain extent, this issue is considered by I.S. Romanchenko, V.O. Shuunkin, G.A. Sakovskiy, S.V. Godz (2019).

The purpose of the paper is to substantiate the rational amount of training hours of students (cadets, officers) using the Weibull-Gnedenko nonlinear mathematical model, which will establish a functional relationship between the training level of students (cadets, officers) and the number of training hours for each military speciality and curriculum.

\section{Materials and Methods}

For the level of training (efficiency) of students (cadets, officers), a certain function $E(x)$ can be taken, which varies depending on the number of training hours completed $x$ according to a curriculum. At the end of the planned educational process, the number of training hours is equal to the planned one. It is accepted that the curriculum contains $x=x_{\text {sch }}$ hours. The achievable level of training, function value $E(x)$, is evaluated based on the results of a check (exam, test). Analysis of changes in the level of training (efficiency, trainability) of students (cadets, officers) showed certain patterns depending on the number of academic hours passed. They manifest themselves in the practical experience of training in the fact that the educational process consists of two periods of training: primary (introductory) and main. It is considered that $E(x=0)=0$ at the beginning of training. After a certain number of academic hours $x_{0}$ students' training level increases unevenly. The process is slower at the beginning and end of the learning process and at any cost $x \neq 0$ the level of training becomes $E(x)$. At the end of the planned period, the training level of students is considered reached, conditionally taken as one, that is $E\left(x=x_{s c h}\right) \rightarrow 1$ according to the curriculum.

It follows that a certain number of training hours $x$ from zero to scheduled $x_{s c h}$ is the range of definition of the function under consideration $E(x)$, that is $0 \leq x \leq x_{s c h}$. Based on this, it is considered that $E(x)$ changes from 0 to 1, i.e. $0 \leq E(x) \leq 1$.

According to the experience of training specialists (Zhdanovich \& Tereshkova, 2020; StatSoft, 2021; Vygodsky, 1962; Nadrljanski et al., 2020; Podakova \& Nechayeva, 2020; Mosiakova, 2021), the initial training period usually does not exceed $15-20 \%$ of the scheduled number of training hours. This ensures that approximately the same level of training is achieved, for example, $E(x) \approx 0.20 \div 0.25$. However, the initial part of classes may be more important $E(x)$, depending on the complexity of a speciality. The main part of the study time should have a practical focus (practical, group classes, laboratory work) (Kennett et al., 2019; Luo et al., 2020; Zhuang et al., 2019; Kubina et al., 2020; Rusev \& Skorikov, 2017; Volobuieva \& Fedyk, 2020). In the future, a mathematical model of the educational process will be illustrated by an example of one semester, a six-month period of study. If we accept that students have a five-day academic week, 6-8 hours of classes per day, then the semester may contain $x=x_{s c h}=700$ hours. We will analyse the functional dependence of the level of training (effectiveness) of students on the number of academic hours completed. Since the learning process is continuous, it means that the function $E(x)$ should also be continuous and twice differentiable. At the same time, based on the dynamics of the training level described above, we can assume that graphically this function can have the form $S$ - similar curve with asymmetrical branches (Figure $1)$. 


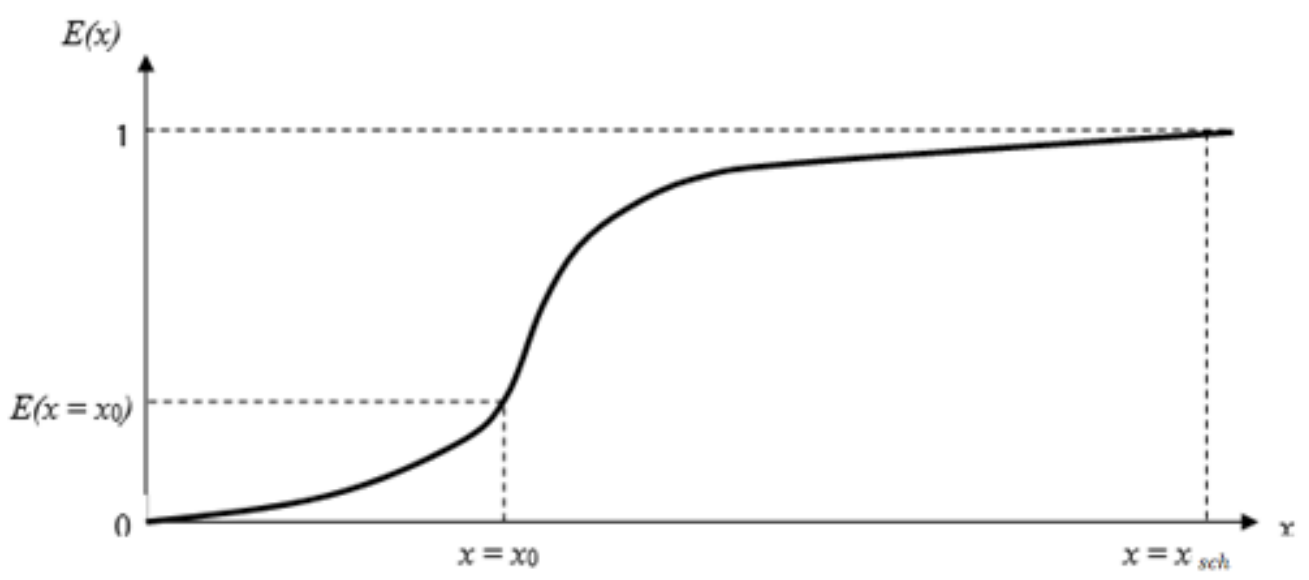

Figure 1. Dependence of the Training Level on the Number of Training Hours (Option)

This graph may correspond, for example, to the dependence of the Weibull-Gnedenko distribution:

$$
E(x)=1-e^{-\lambda \cdot x^{k}},
$$

where $\lambda>0$ is some constant (the first parameter) that affects the shape of the curve; $k \geq 1$ is the exponent (integer or fractional), the second distribution parameter.

According to $k=1$, this distribution coincides with the exponential one. $k=2$ - the Weibull distribution is converted to the Rayleigh distribution. $k>3,5$ - the Weibull distribution practically coincides with the normal distribution law.

\section{Results and Discussion}

As can be seen, the proposed equation (1) meets the requirements for the graph fig. 1, since the curve runs as follows: at the beginning of the learning process $-x=0 ; E(x=0)=0$; at the inflexion point of the graph $-x=x_{0} \approx(0,15 \div$ $0,20) \cdot x_{s c h} ; E\left(x=x_{0}\right)=E\left(x_{0}\right) \approx 0.20 \div 0.25$; at the end of the learning process $-x=x_{\text {sch }} ; E\left(x=x_{\text {sch }}\right)=$ $E\left(x_{s c h}\right) \rightarrow 1$.

A specific type of function determines the position (abscissa) of the inflexion point. In general, the presence of an inflexion point qualitatively reflects the dynamics of the educational process in this case. Up to the inflexion point, with an abscissa $x<x_{0}$ (concave part of the curve), there is a gradual build-up of knowledge to the level of $E\left(x=x_{0}\right)$. In other words, the initial training period is displayed. After inflexion, with an abscissa $x>x_{0}$ (the convex part of the curve), the main training period begins. It slows down at the end of the learning process. As a result, a certain level of student training is achieved $E\left(x=x_{s c h}\right)$.

To find the abscissa of the inflexion point, it is necessary and sufficient that the second derivative of the function (1) has a local extremum $E^{\prime \prime}\left(x_{0}\right)=0$ at this point (Vygodsky, 1962). In this case, the first derivative of the function $E(x)$ equals to:

$$
\frac{d E(x)}{d x}=E^{\prime}(x)=\left(1-e^{-\lambda \cdot x^{k}}\right)^{\prime}=\lambda \cdot k \cdot x^{k-1} \cdot e^{-\lambda \cdot x^{k}}
$$

The second derivative of this function

$$
\frac{d}{d x}\left[\frac{d E(x)}{d x}\right]=\frac{d^{2} E(x)}{d x^{2}}=E^{\prime \prime \prime}\left[(k-1) \cdot \frac{x^{k-2}}{x^{k-1}}-\lambda \cdot k \cdot x^{k-1}\right],
$$

or, if $E(x) \neq 0$,

$$
\left[(k-1) \cdot x^{-1}-\lambda \cdot k \cdot x^{k} \cdot x^{-1}\right]=0
$$

From where: 


$$
1-\frac{k}{k-1} \cdot \lambda \cdot x^{k}=0
$$

So:

$$
x^{k}=\frac{k-1}{k \cdot \lambda}
$$

Then the abscissa of the inflexion point will be determined by the parameter values $k$ and $\lambda$ :

$$
x=x_{0}=\sqrt[k]{\frac{k-1}{k \cdot \lambda}}=\left(\frac{k-1}{k \cdot \lambda}\right)^{\frac{1}{k}},
$$

and the function value:

$$
E\left(x=x_{0}\right)=1-e^{-\lambda \cdot x^{k}}=1-e^{-\frac{k-1}{k}},
$$

This value does not depend on $\lambda$, and is determined only by the value of the index $k$. The index $k$ determines the ordinate of the inflexion point of the curve, i.e. the achievable training level of specialists of a certain profile in the initial period of training. It follows from (5) that for a given $k$ as $\lambda$ increases the value of the abscissa inflexion point $x_{0}$ decreases and vice versa. So, the value of $\lambda$, which is selected, determines the abscissa of the inflexion point (Nadrljanski et al., 2020).

To emphasise the changing features of the function $E(x)$, at the next stage, the question arises of determining the acceptable values for $k$ and $\lambda$. Based on the fact that the dependence of the training level of students on the number of completed academic hours is determined according to (1), the training level of specialists can be set at least the required (needed) level $E(x)_{r e q}=E_{r e q}$. In this case, you can write:

$$
E(x)=1-e^{-\lambda \cdot x^{k}} \geq E(x)_{r e q},
$$

where the required number of training hours is equal to:

$$
x=x_{s c h} \geq\left[-\frac{\ln \left(1-E_{r e q}\right)}{\lambda}\right]^{\frac{1}{k}},
$$

But it was already noted above that the number of academic hours allocated for preparing students was limited and could be about 700 hours. Thus, we write (8) as:

$$
x=x_{s c h}=700 \geq\left[-\frac{\ln \left(1-E_{r e q}\right)}{\lambda}\right]^{\frac{1}{k}},
$$

from here the parameter $\lambda$ can be defined of the functions (1):

$$
\lambda \geq-\frac{\ln \left(1-E_{r e q}\right)}{700^{k}}
$$

On the other hand, from (5) we have:

$$
\lambda=\frac{k-1}{k \cdot x_{0}^{k}}
$$

Combine the equations (10) and (11) and obtain the transcendental equation:

$$
\frac{k-1}{k-x_{0}^{k}}=-\frac{\ln \left(1-E_{r e q}\right)}{700^{k}}
$$

from here the value $k$ can be calculated.

As was assumed above, the abscissa of the inflexion point is $x=x_{0} \approx(0.15 \div 0.20) \cdot x_{\text {sch }}=(105 \div 140)$ hours per $x_{s c h}=700$ hours. If we take the average value of the abscissa of the inflexion point $x=x_{0}=122$ hours, then 


$$
\frac{k-1}{k-x_{0}^{k}}=\frac{k-1}{k-122^{k}}=-\frac{\ln \left(1-E_{r e q}\right)}{700^{k}},
$$

it results in

$$
\frac{k-1}{k-122^{k}} \cdot 700^{k}=-\ln \left(1-E_{r e q}\right)
$$

Or

$$
\frac{700^{k}}{122^{k}}=\frac{700^{k}}{k \cdot 122^{k}}-\ln \left(1-E_{r e q}\right)
$$

The resulting transcendental equation is solved graphically for $k$, for which it can be written in the form of the following equations:

$$
\begin{gathered}
y=\frac{700^{k}}{122^{k}}, \\
y=\frac{700^{k}}{k \cdot 122^{k}}-\ln \left(1-E_{r e q}\right),
\end{gathered}
$$

The joint solution of (16) and (17) will allow us to define $k$ graphically using the calculation of $y$ values. This is shown in Tables (1) and (2).

Table 1. Value of Equation (16) for Different $k$

\begin{tabular}{lllllll}
\hline \multicolumn{2}{l}{ Possible $k$ values } & \multicolumn{1}{l}{} \\
\hline 1 & 1.2 & 1.3 & 1.4 & 1.6 & 1.8 & 2.0 \\
5.74 & 8.13 & 9.68 & 11.55 & 16.36 & 23.21 & 32.92 \\
\hline
\end{tabular}

Table 2. Value of equation (17) for different $k$

\begin{tabular}{llllllll}
\hline Possible values of $E_{\text {req }}$ & \multicolumn{9}{l}{ Possible $k$ values } \\
\cline { 2 - 8 } & 1 & 1.2 & 1.3 & 1.4 & 1.6 & 1.8 & 2.0 \\
\hline 0 & 5.74 & 6.78 & 7.45 & 8.25 & 10.23 & 12.89 & 16.46 \\
0.6 & 6.66 & 7.70 & 8.37 & 9,17 & 11.15 & 13.81 & 17.38 \\
0.95 & 8.74 & 9.78 & 10.45 & 11.25 & 13.23 & 15.89 & 19.46 \\
\hline
\end{tabular}

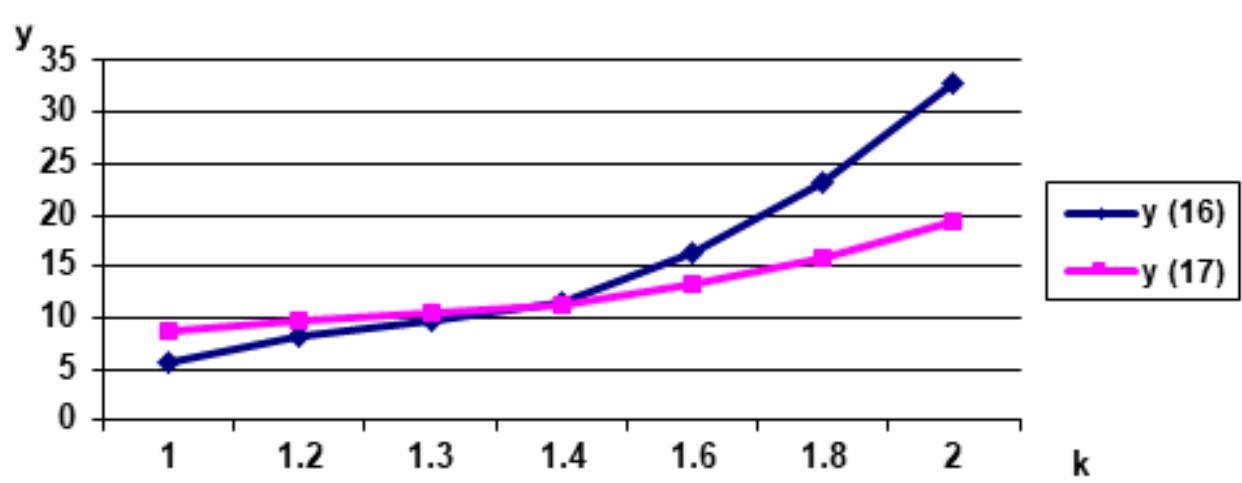

Graphically, the data in Tables 2 and 3 are shown in Figure 2.

Figure 2. Graphical Solution of Equations (16) and (17) 
From the intersection of curves $\mathrm{y}=\frac{700^{k}}{122^{k}}$ and $y=\frac{700^{k}}{k \cdot 122^{k}}-\ln \left(1-E_{\text {req }}\right)$ for example, for $E_{\text {req }}=0.95$, an approximate value $k \approx 1.33$ is determined.

Now you can define the second parameter of the function (1). Let us find it from (20). Accounting for $x=x_{0}=122$ hours and $k \approx 1.33$ :

$$
\lambda=\frac{k-1}{k \cdot x_{0}^{k}}=\frac{1.33-1}{1,33 \cdot 122^{1.33}}=0.000420,
$$

For a deeper analysis of the change in function (1), we calculate its value for different values $x$ within, for example, from 0 to 700 hours and have found values $k$ and $\lambda$ (Table 3).

Table 3. Dependence of the Training Level of Students on Changes in the Number of Academic Hours

\begin{tabular}{|c|c|c|c|c|c|c|c|c|c|c|c|c|c|c|c|c|}
\hline$x$, hour & 0 & 50 & 100 & 122 & 150 & 200 & 250 & 300 & 350 & 400 & 500 & 550 & 600 & 650 & 700 & 700 \\
\hline$E(x)$ & 0 & 0.07 & 0.17 & 0.22 & 0.28 & 0.38 & 0.48 & 0.56 & 0.64 & 0.70 & 0.80 & 0.84 & 0.88 & 0.90 & 0.92 & 0.92 \\
\hline
\end{tabular}

The function graph $E(x)=1-e^{-\lambda \cdot x^{k}}$ is shown in Figure 3 according to Table 3.

As you can see, the accepted function for characterising the educational process meets all the requirements. So, at the beginning of the educational process for $x=0 E(x=0)=0$. For $x=122$ hours and $E\left(x=x_{0}\right)=0.22$ an inflexion point appears that separates the concave part of the curve from the convex one. At the inflexion point, $E\left(x=x_{0}\right)=$ $15-20 \%$ and $x_{s c h}=105-140$ hours. After the end of the educational process $E\left(x=x_{\text {sch }}\right)=700$ hours $=0.92(0.92 \rightarrow$ $0)$.

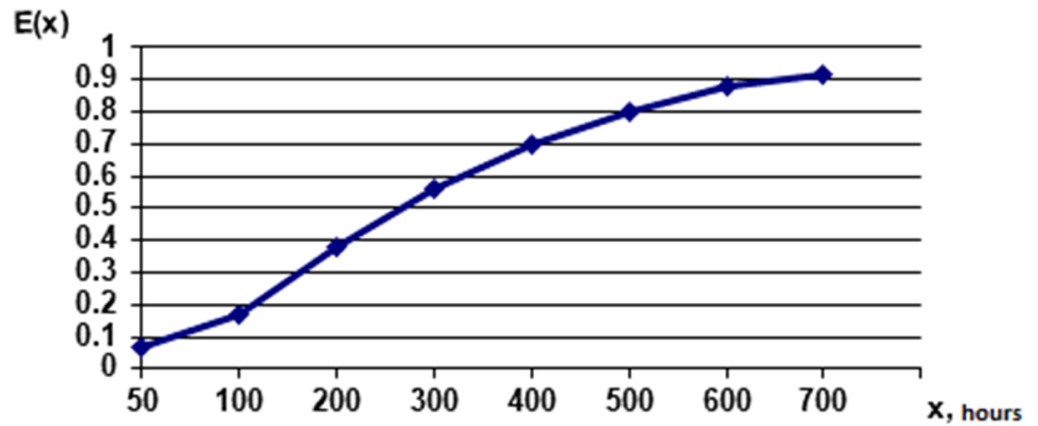

Figure 3. Dependency Graph of the Training Level of Students on Changes in the Number of Academic Hours

Let us check:

1. $E(x)=1-e^{-\lambda \cdot x^{k}}=E\left(x_{\text {sch }}=700\right)=1-e^{-0.00042 \cdot 700^{1.33}} \approx 1-0.08=0.92=E\left(x_{\text {req }}\right)$. That is, if $k \approx$ 1.33 and $\lambda=0.00042$ the function passes through the point with coordinates $x=x_{\text {sch }}=700$ hours and $E(x)=E$ $\left(x_{\text {sch }}\right)=0,92$.

2. The continuity of the function $E(x)$ is confirmed, as well as the area of its definition is a certain number of academic hours from zero to planned in accordance with the curriculum, $0 \leq x \leq x_{s c h}$. The range space of $E(x)$ is a certain number of values from zero to one, $0 \leq E(x) \leq 1$.

Therefore, the function $E(x)$ is obtained, which has $S$ - similar appearance, with the inflexion point $x_{0} \approx 122$ hour, with the initial training period $\left(0 \leq x \leq x_{0}=122\right.$ hour) and the main period $\left(0<x \leq x_{\text {sch }}=700\right.$ hour). The final type of function, i.e. its mathematical model, for the considered educational process if $\approx \approx 1.33$ and $\lambda=0.00042$ will look like:

$$
E(x)=1-e^{-\lambda \cdot x^{k}}=1-e^{-0.00042 \cdot x^{1.33}},
$$


Table 4 shows how the function will change when changing $\lambda, x_{0}$ and constant $k \approx 1.33$.

Table 4. Function $E(x)$ Depending on the Change in Its First Parameter and the Number of Training Hours

\begin{tabular}{clllllll}
\hline Number of training hours, hour & 100 & 200 & 300 & 400 & 500 & 600 & 700 \\
\hline$\lambda=0,0002$ & 0.08 & 0.21 & 0.33 & 0.44 & 0.54 & 0.63 & 0.70 \\
$\lambda=0,00042$ & 0.17 & 0.38 & 0.56 & 0.70 & 0.80 & 0.88 & 0.92 \\
$\lambda=0,0007$ & 0.27 & 0.55 & 0.75 & 0.87 & 0.93 & 0.97 & 0.99 \\
\hline
\end{tabular}

Let us find the abscissa of the inflexion points of these graphs if $k \approx 1.33$. The ordinate remains unchanged at 0.22 .

$$
\begin{gathered}
\text { If } \lambda=0.0002 x=x_{0}=\left(\frac{k-1}{k \cdot \lambda}\right)^{\frac{1}{k}}=\left[\frac{0.25}{0.0002}\right]^{0.725}=210 \text { hours; if } \lambda=0.00042 x=x_{0}=\left(\frac{k-1}{k \cdot \lambda}\right)^{\frac{1}{k}}= \\
{\left[\frac{0.25}{0.00042}\right]^{0.725}=122 \text { hours; if } \lambda=0.0007 x=x_{0}=\left(\frac{k-1}{k \cdot \lambda}\right)^{\frac{1}{k}}=\left[\frac{0.25}{0.0007}\right]^{0.725}=82 \text { hours. }}
\end{gathered}
$$

\section{$E(x)$}

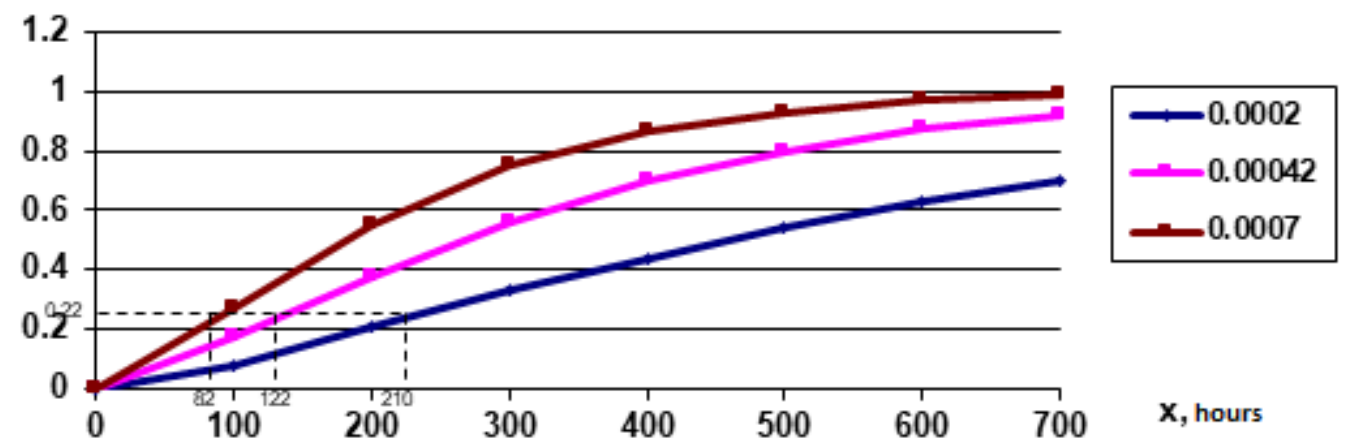

Figure 4. Dependency Graph of the Training Level of Students on Changes in the Number of Academic Hours at Different Values of the First Parameter of the Function $\lambda$

As you can see, the abscissa value decreases if you increase $\lambda$ the number of training hours of the initial period. If the position of the inflexion points changes and at the same value $k$ function value $E(x)(6)$ remains unchanged at the inflexion point since they are determined only by the values of $k>1$ and do not depend on the parameter $\lambda>0$. Setting the value $E\left(x=x_{0}\right) \approx 0.20 \div 0.25$, the law of change in the learning level, that is, the model, depending on the number of passed training hours, will be written as follows:

$$
E(x)=1-e^{-\lambda \cdot x^{1.33}}
$$

\section{Conclusions}

The mathematical model $E(x)=1-e^{-\lambda \cdot x^{k}}$ is proposed to determine the required number of academic hours for the educational process of students (cadets, officers) in higher education institutions. Its type depends on:

- the duration of the initial training period $x=x_{0}$ due to the position of the inflexion point of the function $E(x)$;

- the value of $E\left(x=x_{0}\right)$ at the inflexion point;

- the planned duration of the training period.

Then the parameters ( $k$ and $\lambda$ ), the law of changing the learning level of students, that is, the mathematical model can be calculated in two stages. At the first stage, it is established that the index $k$ of function (1) determines the equally achievable value of the training level of students at the initial period of study. That is the ordinate of the inflexion points of the function. At the same time, with an increase in $k E(x)$ grows, too, and vice versa. At the 
second stage, it is proved that $\lambda$ of functions (1) defines the abscissa of the inflexion point if $k$ is known. At the same time, with an increase in $\lambda$ the value $x=x_{0}$ decreases, the abscissa of the inflexion points shifts to the left when its ordinate value remains unchanged. Varying the parameters $(k$ and $\lambda)$, you can select any type of function (1) that will satisfy the selected conditions $\left(x=x_{0} \approx(0.15 \div 0.20) \cdot x_{s c h}, E\left(x=x_{0}\right)=E\left(x_{0}\right) \approx 0.20 \div 0.25\right)$. The described approach can be used to form the educational process of any educational institution in various specialties.

\section{References}

Avramenko, O., \& Kucher, V. (2020). Improvement of police training at higher educational establishments of the Ministry of Internal Affairs of Ukraine. Social \& Legal Studios, 1(7), 15-23. http://dx.doi.org/10.32518/2617-4162-2020-1-15-23

Belova, S. N. (2008). Ball-rating system for assessing the quality of student training as an element of the quality management system of the educational process in the university. Siberian Pedagogical Journal. Professional Education, R(III), 70-81.

Bogdan, N. V. (2010). Ball-rating system as a method for assessing the quality of education in a university. Bulletin of SUSU, 3, 42-45.

Contribution of Universities to the Bologna Process: Education and culture: Setting up educational structures in Europe. (2021). Socrates-tempus. Retrieved 23.09.2021 from www.https://cuberleninka.ru>stories/

Kennett, D. J., Reed, M. J., \& VandenBerg, T. R. (2019). The importance of perceived university-life balance, hours per week engaged in academic activities, and academic resourcefulness. Teaching and Learning Inquiry, 7(1), 136-153. https://doi.org/10.20343/teachlearninqu.7.1.9

Kubina, E., Bareicheva, M., Stepanova, N., \& Brown, K. (2020). Problems and ways of forming the educational strategy of students in the process of remote learning. Proceedings of the European Conference on e-Learning, 2020-October, 260-269.

Luo, M. N., Bland, P., Stiffler, D., \& Will, J. (2020). Investigating the predictability of academic participation and performance on first-year retention of college freshmen. Universal Journal of Educational Research, 8(5), 2143-2149. https://doi.org/10.13189/ujer.2020.080553

Mosiakova, I. Yu. (2021). Theoretical foundations for the management of multidisciplinary institution of out-of-school education in the conditions of autonomy. Scientific Bulletin of Mukachevo State University. Series "Pedagogy and Psychology", 7(4), 58-65. https://doi.org/10.52534/msu-pp.7(4).2021.58-65

Nadrljanski, M., Pavlinović, M., \& Šimundić, S. (2020). Professional preparation of teachers for new models of student practical training. Smart Innovation, Systems and Technologies, 188, 585-593. https://doi.org/10.1007/978-981-15-5584-8_49

Pavlova, E. S. (2014). Rating and assessment of the level of knowledge of university student. Azimuth of Scientific Research: Pedagogy and Psychology, 4, 90-91.

Podakova, H. Yu., \& Nechayeva, I. A. (2020). Personnel management as a tool for developing a competitive position of higher education institutions. Scientific Bulletin of Mukachevo State University. Series "Economics", 7(2), 40-49. https://doi.org/10.52566/msu-econ.7(2).2020.40-49

Romanchenko, I. S., Shuunkin, V. O., Sakovskiy, G. A., \& Godz, S. V. (2019). Mathematical foundations of the theory of keeping troops by the degree of their readiness. Kyiv: TsNDI ZS of Ukraine.

Rusev, V., \& Skorikov, A. (2017). On solution of renewal equation in the Weibull-Gnedenko model. Reliability: Theory and Applications, 12(4), 60-67.

Starichenko, B. E. (2013). Assessment of the results of educational activities of students in the framework of the information technology model of learning. Education and Science. Yekaterinburg: Federal State Autonomous Educational Institution of Higher Education "Russian State Professional Pedagogical University", 5(104), 113-132.

StatSoft. (2021). Retrieved 23.09.2021 from http://statsoft.ru/home/textbook/default.htm

Volobuieva, O. F., \& Fedyk, A. O. (2020). Methodological aspect of future border guard officers' professional thinking development. Scientific Bulletin of Mukachevo State University. Series "Pedagogy and Psychology", 6(1), 182-189. https://doi.org/10.52534/msu-pp.6(1).2020.182-189 
Vygodsky, M. Ya. (1962). Handbook of higher mathematics. Moscow: State publishing house physical-matematic literature.

Zhdanovich, V. P., \& Tereshkova, A. S. (2020). Use of the Weibulla-Gnedenko model for evaluation of electrical parameters degradation photocells. 56th Scientific Conference of Postgraduates, Masters and Students of BSUIR, 2020, 610-611.

Zhuang, T., Cheung, A. C. K., Lau, W. W. F., \& Tang, Y. (2019). Development and validation of an instrument to measure STEM undergraduate students' comprehensive educational process. Frontiers of Education in China, 14(4), 575-611. https://doi.org/10.1007/s11516-019-0028-2

\section{Copyrights}

Copyright for this article is retained by the author(s), with first publication rights granted to the journal.

This is an open-access article distributed under the terms and conditions of the Creative Commons Attribution license (http://creativecommons.org/licenses/by/4.0/). 